INTIQAD: JURNAL AGAMA DAN PENDIDIKAN ISLAM

ISSN 1979-9950 (print) || ISSN 2598-0033 (online), http://jurnal.umsu.ac.id/index.php/intiqad

DOI: $10.30596 /$ intiqad.v13i2.7600

Vol. 13, No. 2 (December 2021)

\title{
Al-Quran dan Budaya Profetik: Mencetak Insan Kamil di Era Milenial
}

\author{
Nur Alfiana $^{1 *}$,Wahyu Budiantoro ${ }^{2}$ \\ Guru Bahasa Jawa SMK Negeri 3 Purwokerto*1 \\ Dosen Luar Biasa (LB) UIN Prof. K.H. Saifuddin Zuhri Purwokerto ${ }^{2}$ \\ "1email: alfiananur_10@yahoo.com \\ ${ }^{2}$ email: budiantoro.wahyu@yahoo.co.id
}

\begin{abstract}
Document this study aims to identify and explain the prophetic concept in the Quran and its relevance in shaping the personality of human beings in the millennial era, especially in the area of education. This study uses a qualitative method. Data sources are divided into two, primary and secondary. Primary data were obtained from verses of the Quran which talk about the concept of prophetic and insan kamil. While secondary data was obtained from several scientific journals and books that talk about similar themes. The results of the study are, firstly, the Quran contains many prophetic and human concepts, secondly, the Quran also talks about the concept of education in prodemic culture, and thirdly, the great qualities of the Prophet Muhammad such as sidiq, amanah, fatah, become guidelines for millennials to develop human personality.
\end{abstract}

Keyword: Al-Quran, Prophetic, Insan Kamil
Artikel Info

Received:

02 September 2021

Revised:

07 October 2021

Accepted:

26 November 2021

Published:

04 December 2021

\begin{tabular}{l}
\hline Abstrak \\
\hline Tujuan riset ini adalah untuk mengidentifikasi dan \\
menjelaskan konsep profetik di dalam Al-Quran dan \\
relevansinya dalam membentuk kepribadian insan kamil di \\
era milenial, utamanya pada wilayah pendidikan. Penelitian \\
ini menggunakan metode kualitatif. Sumber data dibagi \\
menjadi dua, primer dan sekunder. Data primer diperoleh \\
dari ayat-ayat Al-Quran yang berbicara mengenai konsep \\
profetik dan insan kamil. Sedangkan data sekunder \\
diperoleh dari beberapa jurnal ilmiah dan buku yang \\
berbicara mengenai tema serupa. Hasil penelitian adalah, \\
pertama, Al-Quran mengandung banyak konsep profetik \\
dan insan kamil, kedua, Al-Quran juga berbicara mengenai \\
konsep pendidikan dalam budaya prodetik, dan ketiga, sifat \\
\hline \hline
\end{tabular}


agung Nabi Muhammad seperti sidiq, amanah, fatanah, menjadi pedoman bagi milenial untuk mengembangkan kepribadian insan kamil.

\section{Kata Kunci: Al-Quran, Profetik, Insan Kamil}

\section{A. Pendahuluan}

Sebagai ciptaan Allah, manusia diberi tugas yang mulia (Sada, 2016). Meskipun diciptakan dari tanah, manusia memiliki kedudukan tinggi di antara makhluk Allah yang lain. Dalam agama Islam, manusia diposisikan sebagai ahsanu taqwim, yakni sebaik-baiknya ciptaan dan agar dipelihara oleh manusia (khalifah).

Dalam Al-Quran, masih dalam tinjauan Sada (2016), konsep manusia tidak dijelaskan secara rinci muasalnya. Hanya saja terdapat ayat-ayat yang berbicara mengenai penciptaan manusia, di antaranya: Q.S. Nuh: 17, Q.S. ashShaffat:11, Q.S. al-Mukminuun: 12-13, Q.S. ar-Rum: 20, Q.S. ali-Imran: 59, Q.S. as-Sajdah: 7-9. Selain itu, terdapat juga ayat-ayat penciptaan manusia pada Q.S. al-Mukimunun: 21-26 dan alAnkabut: 2-3 (Departemenen Agama Republik Indonesia, 2003).

Satu surah dalam Al-Quran di atas menunjukan bahwa Allah memiliki kuasa atas penciptaan manusia. "Apakah manusia itu mengira bahwa mereka dibiarkan (saja) mengatakan: "Kami telah beriman", sedang mereka tidak diuji lagi? Dan sesungguhnya Kami telah menguji orang-orang sebelum mereka. Maka sesungguhnya Allah mengetahui orang-orang yang benar dan sesungguhnya Dia mengetahui orangorang yang dusta." (al-Ankabut: 2-3). Oleh karena itu, Harun Yahya (2001) menyebut bahwa manusia harus selalu mewujudkan kuasa Allah dalam setiap perilaku dan misi khalifah yang berada di pundaknya.

Selain ditinjau dari Al-Quran, manusia juga didefinisikan oleh para filosof. Misalnya menurut Demokritos (460-360 SM). Dia berpendapat, dalam riset Kurniawati dan Bakhtiar (2021), "berpikir" merupakan ciri khusus pada manusia. Sedangkan, menurut Charles Darwin (1809-1882), pendapat ini muncul dalam riset Akrabi (2005), yang menyatakan bahwa evolusi hayat mempengaruhi bentuk manusia Berbeda lagi menurut ilmuwan pendidikan. Masih 
dalam dalam penelitian Kurniawati dan Bakhtiar (2021), manusia disebut sebagai makhluk yang mesti menerima edukasi.

Artinya, manusia memiliki visi dan misi pendidikan sebagai khalifah. Dimensi inilah yang harus senantiasa dioptimalkan manusia. Mengapa demikian? H.M. Rasjidi (1984) memberikan alasan yang rasional. Dia menjelaskan bahwa:

"Jika diamati lebih mendalam sifat-sifat dan karakter manusia, khususnya bahwa manusia itu mempunyai bahasa yang teratur, mempunyai keahlian untuk berbicara, berpikir, memiliki kepekaan sosial, mempunyai apresiasi estetik dan rasa yang tinggi serta mampu melakukan ritual ibadah kepada Sang Pencipta maka wajarlah jika para filosof agama (Yahudi, Kristen, Islam) mendefinisikan manusia sebagai makhluk yang unik dari asal yang suci, bebas dan dapat memilih".

Bila mengamati pendapat H.M. Rasjidi di atas, artinya, manusia dipenuhi dengan kemampuan simbolik dan motorik untuk menciptakan pendidikan (juga tatanan dunia) yang beradab dan selaras dengan visi ketuhanan. Sebab, manusia yang bependidikan berarti mampu memaksimalkan kemampuan berpikir, berbicara, berbahasa dan rasa dalam setiap kehidupan. Oleh karena itulah, manusia disebut sebagai insan kamil.

Sebagai objek kajian, insan kamil sudah cukup jamak dibahas. Rifa'i (2016) mengutarakan bahwa insan kamil berasal dua kata, "insan" dan "kamil". Secara bahasa, insan kamil dapat berarti manusia yang sempurna. Kata "insan" bermakna manusia merupakan tempatnya lupa dan salah. Sebagai kata yang menunjukan pada arti manusia, kata "insan" secara langsung mengarah kepada hakikat manusia. Sedangkan, kondisi yang sempurna dan sempurnanya zat dan sifat ditujukan untuk makna "kamil".

Selain itu, riset Ahmad, Wahid dan Ali (2020) menunjukkan bahwa watak tokoh utama dalam novel tersebut merepresentasikan sosok insan kamil, yaitu insan khalifah atau insan rabbani. Abidin dan Zulfah (2018) pada penelitiannya berjudul "Konsep Pendidikan Akhlak Sebagai Pembentukan Insan Kamil dala Perspektif Naquib Al-Attas" mengemukakan bahwa ciri-ciri insan kamil ialah berfungsinya akal secara optimal dan berfungsi intuisinya. 
Ibnu 'Arabi, dalam penelitian Royadi mengurai konsep insan kamil menjadi empat kategori, yakni: 1) nilai karkater terhadap Tuhan, 2) nilai karakter terhadap diri sendiri, 3) nilai karater terhadap manusia, 4) nilai karakter terhadap manusia (Royadi, 2019). Sedangkan menurut Al-Jili, insan kamil bukan hanya persoalan bentuk, melainkan citra Allah seutuhnya secara sempurna. Sehingga, pada dirinya tercermin nama dan sifat agung Allah secara utuh (Kurniawati, 2021).

Apa yang ditemukan dalam riset sebelumnya menujukan bahwa konsep insan kamil akan selalu berkaitan dengan hubungan manusia dengan Allah, sesama manusia dan alam semesta. Semua unsurnya berkelindan membentuk kepribadian yang mulia. Kepribadian semacam itulah yang diharapkan dalam setiap proses pendidikan. Sebagaimana dicontohkan oleh Nabi Muhammad (profetik). Spirit kenabian tidak hanya berhenti pada level konsep, melainkan aplikasi (praktis).

\section{B. Metode Penelitian}

Kualitatif digunakan sebagai metode penelitian ini. Karakteristik kualitatif adalah seni dan kerap disebut sebagai metode interpretive, karena berkaitan dengan penafsiran terhadap data riset (Sugiyono, 2007). Sumber data dalam penelitian ini berupa data primer dan sekunder. Data primer berupa pendokumentasian ayat-ayat Al-Quran yang berbicara mengenai konsep profetik dan insan kamil. Sedangkan, data sekunder diperoleh melalui jurnal ilmiah atau buku yang berkenaan dengan kajian profetik atau insan kamil. Analisis dalam penelitian menggunakan deskriptif kualitatif. Sebab, data primer berupa ayat-ayat Al-Quran diposisikan sebagai basis, dengan pendapat para pemikir atau peneliti sebelumnya sebagai penguat argumentasi.

\section{Hasil dan Pembahasan}

Konsep "Manusia Profetik" dalam AlQuran

Manusia merupakan makhluk sosial yang dalam bahasa latinnya dinamakan homo socius, yakni manusia yang tidak bisa hidup sendiri karena manusia membutuhkan satu sama lain. Al-Quran juga menyentil berkaitan dengan hal tersebut secara samar melaui Q.S al-Alaq ayat 2: Yakni menciptakan manusia dari segumpal darah atau sesuatu yang menempel pada rahim 
yang mana ayat ini dapat dipahami sebagai sesuatu yang diciptakan selalu bergantung pada orang lain (Shihab, 2007). Al-Qura'an merupakan kitab umat Islam yang selalu mengajak pada kebenaran, memberantas segala penindasan, dan membentuk karakter yang positif. Sebagaimana dalam salah Q.S al-Isra: 9: Sesungguhnya Al-Quran ini memberikan petunjuk kepada (jalan) yang lebih lurus dan memberi khabar gembira kepada orang-orang mu'min.

Dalam upaya pembentukan dan pengolahan karakter al-Quran dapat menjadi sebuah rujukan yang mutakhir. Hal ini dapat kita pahami dengan melihat pengaruh Al-Quran terhadap bangsa Arab. Hal itu terbukti dengan ketangguhan para sahabat, tabiin, tabiin tabiin serta ulama yang berpegang teguh terhadap Al-Quran sepanjang hidup mereka.

Pesan tersebut yang menguatkan terhadap mental dan karakter agar teguh dalam menghadapi berbagai peoblematika dan tantangan zaman (Tafsir Al-Quran Tematik, 2010). AlQuran pula menjadi rujukan umat Islam (way of life) dan telah menjelaskan berbagai tuntunan dalam kehidupan, mulai dari perkara syariat hingga bab muamalah yang baik (Junaedi, 2019). Tidak perlu diragukan lagi, Al-Quran begitu pekat mengandung kekuatan profetik yang begitu mendalam. Implikasi dari nilai-nilai spiritualitas yaitu mampu menumbuhkan perbaikan karakter, jiwa serta menghaluskan budi pekerti, mempertajam intuisi. Apabila kita merenung mendalam pada surat alMuzammil (1-10) dan surat al-Muddatsir (4-7) maka, akan tercermin spirit maupun pesan kenabian (profetik) ihwal pembentukan spiritualitas dan karakter seseorang.

\section{Makna Profetik}

Secara kebahasaan atau etomologi istilah "profetik" berasal dari bahasa Inggris yakni dari kata prophetic dan Arab, yakni nabiy yang kemudian membentuk kata nubuwah (Roqib, 2016a).

Dua makna bisa diperoleh dari konsep tersebut, Rasul (diberi perintah dakwah) dan Nabi (yang tidak diberi perintah dakwah) (Roqib, 2016a). Pada hakikatnya kenabian atau profetik merupakan salah satu wujud kepemimpinan yang disematkan oleh Tuhan pada manusia pilihannya (Subagja, 2010). 
Kata prophet (nabi) dan prophetic bermakna (kenabian) (Dagum, 2010) juga bermakna ciri yang dimiliki Nabi sebagai cermin spirit individual dan kolektif untuk gerakan revolusi sosial. Nabi Ibrahim melawan Raja Namrud dan Nabi Musa melawan Fir'aun bisa dijadikan contoh. Nabi Saw. Juga mengawal revolusi sosial berupa bimbingan kepada kaum miskin dan budak untuk bangkit dari ketertindasan dan ketidakadilan.

Ali Syariati mengatakan para nabi tidak hanya mengajarkan dzikir dan doa melainkan ia datang dengan ideologi pembebasan. Kata prophetic dalam bahasa Yunani juga memiliki makna seseorang yang berbicara memproklamasikan diri. Makna tersebut juga bisa diartikan sebagai seseorang yang visioner (Roqib, 2016b). Sehingga, pemaknaan profetik bersifat prediktif, akrena ketinggian hikmah yang dimiliki nabi (Umam, 2018).

Pemikiran tersebut merupakan filsafatnya Suhrawardi dan Ibnu Arabi. Di satu sisi juga mengembangkan pemikiran dari cendekiawan Indonesia yakni Kuntowijoyo. Dengan berpijak pada Q.S ali-Imran: 9, bahwa umat Islam adalah komunitas unggul (khaira ummat) apabila umat Islam mampu menjalankan amar ma'ruf (humanisasi), nahi munkar ( liberasi), serta beriman (transedensi). Paradigma profetik memberikan keseimbangan antara kemanusiaan dan ketuhanan. Pertama, kemanusiaan merupakan cara pandang yang lebih condong terhadap aspek akhlak yang baik pada manusia (Ahimsa-Putra, 2017). Kedua, pembebasan adalah implementasi alnahy an al-munkar. Liberalisasi sebenarnya konsekuensi logis dari praktik humanisasi, ini bermakna bahwa humanisasi menyaratkan di dalamnya liberalisasi, yakni penghapusan penindasan terhadap manusia. Ketiga, transendensi adalah implemetasi iman terhadap Allah SWT. Aspek ini menegaskan profetik mencakup visi jangka panjang yang kelak akan dipertangung jawabkan kepada Allah SWT.

Budaya sebagai landasan untuk bergerak dalam dalam kehidupan yang positif dan produktif (Roqib, 2016a). Di samping itu, perlu adanya paradigma nilai-nilai kenabian yakni: a) tauhid dan tasawuf, b) kenabian (prophet) sebagai model uswatun hasanah, c) memiliki 
dasar akal yang disandarkan pada Allah SWT.

Al-Quran menerangkan bahwa sosok Nabi menjadi hamba yang sehat lahir batin. Dia diberi petunjuk oleh Allah dan malaikat serta juga mengimplementasikannya dalam kehidupan di tengah umat. Kuntowijoyo dalam bukunya berjudul Paradigma Islam: Interpretasi untuk Aksi menyatakan perlunya ilmu sosial profetik yang memberi tuntunan ke arah mana transformasi itu dilakukan, Pandangan Kuntowijoyo berdasarkan atas surat ali-Imran: 110. Kandungan ayat tersebut memuat nilai yang akan melahirkan ilmu sosial profetik menjadi berkarakter (Roqib, 2016a).

\section{Pendidikan dalam Budaya Profetik: Mencetak Insan Kamil di Era Milenial} Permasalahan dalam dunia pendidikan menjadi diskusi yang santer. Pendidikan dari bila ditinjau dari epistemologi, ontologi dan aksiologi selalu berkembang dinamis. (Umam, 2017). Hal ini dikarenakan pendidikan selalu responsif terhadap perubahan zaman dan berupaya untuk memunculkan terobosan dalam mengatasi berbagai persoalan. Namun, pada kenyataannya, dominasi ideologi masih besar. Maka itu, dibutuhkan terobosan yang kreatif dalam pendidikan. Perlu adanya konsep pendidikan yang akomodatif sebagai paradigma.

Konsep pendidikan tersebut haruslah dirancang unutk kebutuhan manusia, dengan tetap bersendikan nilai Islam. Pendidikan Islam tidak hanya sebagai proses penyemaian nilai-nilai karakter yang bertujuan untuk membentengi diri, melainkan menjadi kekuatan pembebasan (liberating force) dari himpitan perekonomian, sosial dan budaya (Maarif, 2010). Sifat ortodoksi masih mendominasi dalam tujuan pendidikan Islam. Sehingga muncul dikotomi antara pendidikan agama dengan pendidikan umum, bahkan memposisikannya secara oposisional.

Pendidikan Islam menjadi bagian penting dari sistem pendidikan nasional. Hal ini dibuktikan dengan adanya sekolah-sekolah yang bernafaskan Islam seperti Bustanul Athfal (TK), Madrasah Ibtidaiyah (SD), Madrasah Tsanawiyah (SMP), Madrsah Aliyah (SMU) dan Perguruan Tinggi Islam baik dikelola swasta ataupun negeri. Serta ada pesantren baik salaf maupun modern. Berbagai potensi tersebut menjadi 
sesuatu yang menggembirakan bagi perkembangan masa depan umat Islam. Harapan dari munculnya sekolah bernapaskan pendidikan Islam yakni terbinanya generasi insan kamil (manusia paripurna), yakni pendidikan yang tidak hanya berfokus pada ketiga aspek berupa aspek kognitif, afektif dan psikomotorik (Roqib, 2016b).

Konsep pendidikan profetik, dapat kita cermati dalam Q.S al-Ahzab: 21: "Sesungguhnya telah ada pada (diri) Rasulullah itu suri teladan yang baik bagimu (yaitu) bagi orang yang mengharap (rahmat) Allah dan (keselamatan) hari kiamat dan dia banyak mengingat” (Q.S Al-Ahzab ayat 21). Profetik sebenarnya memilik makna kenabian yang digali dari cara hidup Rasululloh dalam hidupnya. Profetik diklaim sebagai sebuah grand desain karakter yang adaptif dalam bentuk tatanan pengembangan karakter (character building) dirinya. Nilai karakter ini seharusnya diimplementasikan dalam seluruh aspek penting kehidupan (Mujtahid, 2011). Sedangkan menurut Syafi'i Antonio nilai profetik merupakan esensi manusia dalam aktivitas kehidupannya, mulai dari berdagang, berpolitik, berkeluarga, serta aktivitas lainnya. Kendati demikian, masyarakat Indonesi melupakan esensi dri sifat-sifat kerasulan Muhammad Saw.

Nilai-nilai profetik selalu merujuk pada sosok Rasulullah (Mujtahid, 2011), yang mampu membentuk karakter Islami yakni: Pertama, sidiq (Integrity) yaitu karakter jujur. Sedangkan apabila dalam arti luas, sidiq dapat diartikan sebagai kejujuran. Kejujuran menjadi modal dasar dan wujud keimanan pada Allah Swt. Sifat jujur dapat dirangsang melalui cara memperoleh rizki yang halal. Melalui rizki yang halal maka, pembentukan integritas dalam diri seseorang dapat dibangun.

Kedua, amanah (responsible) dapat dimaknai sebagai sifat yang dipercaya dan bertanggungjawab. Sifat amanah mampu mendorong manusia untuk berlaku adil. Sifat amanah akan muncul seiring dengan banyaknya tugas seseorang yang diembannya. Fathanah (Smart) merupakan karakter seseorang dengan capacity building yang baik, meliputi kecerdasan spiritual dan intelektual (skillfull). Kecerdasan menuntun manusia untuk dapat memecahkan masalah. Sifat tersebut dapat terwujud apabila seseorang terus menerus belajar dalam hidupnya. Belajar 
dapat dari pengalaman pribadi, pengalaman orang lain, buku serta berbagai sumber lainnya (Roqib, 2016b).

Ketiga, tabligh (communicative) dapat pula diartikan sebagai kemampuan komunikasi yang efektif. Komunikasi diyakini menjadi kunci. Berani berpendapat dan berbicara pada ranah sosial menjadi polanya.

Ketiga sifat-sifat tersebut merupakan sifat profetik atau kenabian. Sifat-sifat yang sepatutnya menjadi pedoman seseorang untuk membentuk karakter diri (character building) demi meningkatkan kualitas diri secara vertikal (hablun min Allah) maupun horizontal (hablun min al-nas). Tentu dengan senantiasa berdoa dan mengharap petunjuk dari dari Allah Swt (Habiba, Sulhatul, 2018).

Dari pemaparan di atas kita dapat pahami bersama bahwa iman ialah meyakini sepenuh hati dan perilaku kepada Allah Swt. Iman kepada Malaikat dengan meyakini adanya malaikat-malaikat Allah. Iman kepada Nabi dan Rasul berarti kita meyakini dengan sepenuh hati bahwa Rasulullah itu benar-benar utusan Allah yang membawa rahmat bagi seluruh alam. Iman pula terhadap kitab-kitab Allah yang diwahyukan kepada rasul-rasul Allah dan iman terhadap hari akhir serta terhadap Qodho (ketetapan Allah) dan Qodar (kekuasaan) (Umam, 2018).

Pendidikan Islam dalam implementasi ranah budaya begitu dibutuhkan sebagai bagian dari pembentukan jati diri manusia melalui lingkungan dengan lambang pendidikan yang religius yang dimilikinya. Saat ini dunia Islam perlu pengkayaan lambanglambang budaya. Hal ini mengingat simbol budaya akan lebih diterima ketimbang agama, termasuk dalam zaman kolinial atau dalam istilah teori kritis post-modern. Beragamnya budaya yang ada di Indonesia merupakan bentuk potensi ekonomi lokal kreatif yang turut serta dalam masa depan bangsa. Budaya yang dijadikan bahan tinjauan kaijainnya akan dapat memantulkan sifat menerima dan melestarikan. Sebab pendidikan pada hakikatya adalah produk dari peradaban budaya. Sehingga kebudayaan dan pendidikan adalah mata rantai yang saling bertautan, mengisi, dan saling berkaitan hingga mempunyai intern relative (Rifa'i, 2016).

Pendidikan profetik memberi efek transformasi, untuk budaya dan individu. Transformasi individu idealnya lebih 
dahulu tumbuh, sebelum yang lainnya. Hal itu menjurus pada cara pandang psikologi perkembangan, yakni pada perkembangan manusia sebagai pribadi individu, mulai dari hidup sampai mati. Perkembangan yang dimaksud yakni proses yang visioner dan beradab. Sedang dalam teori psikodinamika komponen dasar yang bersifat sosiofektif berpengaruh bagi kepribadian dan jiwa manusia di tengah lingkungan sendiri (Roqib, 2016a).

Bermula dari pendidikan profetik, nantinya pada setiap cabang keilmuan yang lain juga berdasar pada landasan profetik misalnya psikologi profetik dan kedokteran profetik. Ilmu kedokteran profetik akan melahirkan transformasi pada tataran masyarakat. Disiplin profetik lainnya, yaitu psikologi profetik mampu menghasilkan individu yang berkompeten pada ranah kolektif.

Sifat rasul Muhammad Saw seperti sidiq, amanah dan fatonah itulah yang harus dibangun generasi milenial. Generasi yang memiliki kekuatan sumber daya informasi yang luas dan adaptatif. Sehingga, bila kemampuan adaptatifnya dilengkapi dengan sifatsifat kenabian tersebut maka, bisa digolongkan menjadi insan kamil, sebagaimana firman Allah dalam Q.S. al-Anfal: "Dan siapakanlah untuk menghadapi mereka kekuatan apa saja yang kamu sanggupi dan dari kuda-kuda yang ditambat untuk berperang (yang dengan persiapan itu) kamu menggentarkan musuh Allah dan musuhmu".

\section{Simpulan}

Menjadi manusia insan kamil tentunya harus berdasarkan Al-Quran, Hadits dan tuntunan para ulama. Artinya, menjadi insan kamil adalah perintah Allah yang harus diusahakan sungguhsungguh oleh setiap manusia. Salah satu teladan yang bisa diambil contoh adalah Nabi Muhammad Saw. Setiap manusia yang meneladani perjuangan dan sifatsifat agungnya (sidiq, amanah, fatanah), pasti akan menjadi manusia insan kamil. Oleh sebab itu, budaya profetik (kenabian) harus senantiasa dihadirkan dalam setiap fase kehidupan manusia, utamanya pada wilayah pendidikan. Pendidikan profetik (kenabian) mengajarkan manususia, khususnya generasi milenial, untuk memiliki keimanan yang kuat, sifat jujur, adaptatif, dan responsif terhadap peluang dan tantangan zaman. 


\section{E. Daftar Pustaka}

Abidin, Fauzi Khoirul, M. A. Z. (2018). Konsep Pendidikan Akhlak Sebagai Pembentukan Insan Kamil Dalam Persepktif Naquib Al-Attas. Journal of Education and Management Studies, 1(1), 51-60.

Ahimsa-Putra, H. S. (2017). Paradigma Profetik Islam: Epistemology, Etos dan Model. Gadjah Mada University Press.

Ahmad, Zaidi bin, Azhar Abdul Wahid, A. H. A. (2020). Kerasulan Insan Kamil Membentuk Modal Insan dalam Novel Iman. Rumpun Jurnal Persuratan Melayu, 8(2), 16-27.

Akrabi, M. S. (2005). Pendidikan Agama Islam Untuk Perguruan Tinggi. Gunung Pesagi.

Dagum, M. (2010). Kamus Besar Ilmu Pengetahuan. Lembaga Pengkajian Nusantara.

Departemen Agama Republik Indonesia. (2003). Al-Quran dan Terjemahannya. Jamunu.

Habiba, Sulhatul, K. S. (2018). Pendidikan Profetik dan Perannya dalam Menangkal Dampak Negatif Teknologi di Mlangi Yogyakarta. Al-Riwayah: Jurnal Kependidikan, 10(2), 325-334.

Junaedi, D. (2019). Tafsir Kebahagiaan : Menyingkap Makna Kebahagiaan
Perspektif Tafsir Psiklogi.

Rahmadina Publishing.

Kurniawati, E. dan N. B. (2021). Manusia Menurut Konsep AlQuran dan Sains. Dirasah, 4(1), 101-117.

M, U. (2018). Recontruction of Integrative Islamic Education inThe Transformative Profetical Education Framework. Proceeding: Annual Conference for Muslim Scholars.

M, U. (2017). Strategi Alternatif Memajukan Lembaga Pendidikan Islam di Pedesaan Berbasis Sekolah Excellent Perspektif Kompetitif Kontemporer. Proceedings: Annual Conference for Muslim Scholars, 769-776.

Maarif, A. S. (2010). Islam dalam Bingkai Kemanusiaan dan Keindonesiaan. Mizan.

Mujtahid. (2011). Tujuh Karakteristik Kepemimpinan Profetik. UIN Malang.

Rasjidi, H. . (1984). Persoalan-Persoalan Filsafat. Bulan Bintang.

Rifa'i, M. K. (2016). Internalisasi NilaiNilai Religius Berbasis Multikultural Dalam Membentuk Insan Kamil. Jurnal Pendidikan Agama Islam, 4(1), 117-133. 
INTIQAD: JURNAL AGAMA DAN PENDIDIKAN ISLAM

ISSN 1979-9950 (print) || ISSN 2598-0033 (online), http://jurnal.umsu.ac.id/index.php/intiqad DOI: 10.30596/intiqad.v13i2.7600

Vol. 13, No. 2 (December 2021)
Roqib, M. (2016a). Filsafat Pendidikan

Profetik: Pendidikan Islam integrative dalam perspektif Kenabian Muhammad. An-Najah Press.

Roqib, M. (2016b). Ilmu Pendidikan Islam: Pengembangan Integratif di Sekolah Keluarga dan Masyarakat. LkiS.

Royadi, A. (2019). Pendidikan Karakter Berbasis Tasawuf: Studi Konsep Insan Kamil Ibnu Arabi. Universitas Islam Negeri Maulana Malik Ibrahim.

Sada, H. J. (2016). Manusia Dalam Persepektif Agama Islam. AlTadzkiyyah: Jurnal Pendidikan Islam, 7.

Shihab, Q. (2007). Wawasan Al-Quran Tafsir Tematik atas Berbagai Persoalan Umat. Mizan.

Subagja, S. (2010). Paradigma NilaiNilai Kepemimpinan Profetik (Spirit Implementasi Model Kepemimpinan Di Lembaga Pendidikan Islam). Progresiva, 3.

Sugiyono. (2007). Metode Penelitian Kuantitatif, Kualitatif dan R\&D. Alfabeta.

Tafsir Al-Quran Tematik. (2010).

Pendidikan, Pengembangan

Karakter, Dan Pengembangan
Sumber Daya Manusia. Lajnah Pentashihan Al-Quran.

Yahya, H. (2001). Mengenal Allah Lewat Akal. Robbani Press. 